\title{
IDENTIFICATION OF MALE FACTOR INFERTILITY USING A NOVEL SEMEN QUALITY SCORE AND REACTIVE OXYGEN SPECIES LEVELS
}

\author{
Kiran P. Nallella, Rakesh K. Sharma, Shyam S. R. Allamaneni, and Ashok Agarwal
}

Nallella KP, Sharma RK, Allamaneni SSR, Agarwal A. Identification of male factor infertility using a novel semen quality score and reactive oxygen species levels. Clinics. 2005:60(4):317-24.

PURPOSE: To determine whether patients with male factor infertility can be accurately identified by calculating a novel semen quality score and measuring levels of reactive oxygen species during routine infertility screening.

METHODS: Semen samples from 133 patients and 91 healthy donors were evaluated with manual and computer-assisted semen analysis. A principal component analysis model was employed to calculate a semen quality score. In brief, this score was calculated by base 10 logarithms multiplied by varying weights given to 9 sperm parameters. Reactive oxygen species levels were measured using chemiluminescence assay.

RESULTS: The semen quality score had a sensitivity of $80.45 \%$ and accuracy of $77 \%$ at a cutoff of 93.1 in identifying patients with male factor infertility. The area under the receiver operating characteristic curves for the semen quality score was $84.28 \%$ (95\% CI: $65.22 \%-100 \%$ ). Reactive oxygen species levels [log10 (reactive oxygen species +1$)$ ] were significantly higher in male factor infertility patients. Reactive oxygen species had a sensitivity of $83.47 \%$ and specificity of $60.52 \%$ with an accuracy of $75 \%$ at a cutoff of 1.25 in identifying male factor infertility patients. The area under the receiver operating characteristic curve for reactive oxygen species levels was 78.92\% (95\% CI: 72.60\%-85.23\%). semen quality scores were significantly and negatively correlated with reactive oxygen species levels in the donors and the male factor infertility patients.

CONCLUSIONS: The semen quality score and reactive oxygen species levels in semen samples appear to be strongly associated with male factor infertility. Because both of these parameters are more sensitive than individual sperm parameters in identifying male factor infertility, they should be included in routine infertility screening.

KEYWORDS: Spermatozoa. Male factor infertility. Semen quality score. Reactive oxygen species. Sperm parameters.

Infertility affects an estimated $10 \%$ to $15 \%$ of couples, and in approximately half of these cases, the defect can be traced to the man. ${ }^{1}$ Although considerable progress has been made towards understanding sperm physiology and the biology of gamete interaction, more information is needed to determine which tests, if any, can accurately predict sperm quality.

Center for Advanced Research in Human Reproduction, Infertility, and Sexual Function, Glickman Urological Institute and Department of Obstetrics-Gynecology, Cleveland Clinic Foundation - Cleveland, Ohio. E-mail: agarwaa@ccf.org

Received for publication on March 25, 2005.

Accepted for publication on May 11, 2005.
Semen analysis remains the most important clinical laboratory test available for the evaluation of male infertility. ${ }^{2}$ It is clear that both sperm concentration and the number of motile and morphologically normal spermatozoa are significant factors influencing in vivo and in vitro fertilization. ${ }^{3-5}$ In addition, studies have suggested that computerassisted semen analysis (CASA) can precisely and reliably estimate sperm kinematics, which in turn, significantly relate to the fertilization rate in vitro and the time to conception. ${ }^{6-9}$

Although semen analysis constitutes an essential component of infertility evaluation, it may still fail to detect subtle sperm defects present in patients with male factor infertility (MFI). Although estimates vary, the likelihood for 
normal spermiograms in these cases is approximately $15 \% .^{10}$ Identifying diagnostic measures for MFI that are easy to perform, relatively inexpensive, and able to provide an accurate diagnosis is necessary.

Because semen parameters are interrelated, they can be reduced to 2 semen scores termed the overall semen quality (SQ) and relative quality (RQ) scores. ${ }^{11}$ The SQ score was developed by principal component analysis of 9 individual sperm parameters, and has been reported as a highly reliable and efficient tool for clinicians who screen for and diagnose MFI. ${ }^{11}$

Furthermore, studies have shown that $40 \%$ to $88 \%$ of nonselected infertile patients have high levels of seminal reactive oxygen species (ROS). ${ }^{12}$ Uncontrolled and excessive production of ROS may be one of the major factors leading to infertility. ${ }^{12-16}$ It appears, therefore, that the presence of oxidative stress in infertile normozoospermic men may help explain previously unexplained cases of infertility that were otherwise attributed to female factors. ${ }^{17}$

The purpose of this study was to: 1) examine improved parameters in identification of MFI patients during infertility screening, 2) establish cutoff values for the SQ score and ROS levels that identify patients with MFI, and 3) determine the relationship between the SQ score and levels of ROS in patients with MFI.

\section{METHODS}

The Institutional Review Board of The Cleveland Clinic Foundation approved the study. Medical charts of the patients attending the infertility clinic for infertility evaluation were reviewed.

\section{Study population}

The patient population consisted of 133 MFI patients. All patients had a history of at least 1 year of primary or secondary infertility with their current partner and had completed a basic evaluation that included medical history, a physical examination, and at least 2 semen analyses. On occasion, the patient provided more than 1 semen sample. Semen samples $(n=264)$ were divided into 4 groups based on results from all semen analyses: oligozoospermic $(\mathrm{n}=$ $61)$, asthenozoospermic $(n=96)$, teratozoospermic $(n=69)$, and oligoasthenoteratozoospermic (OAT, $\mathrm{n}=38){ }^{2}$ Subjects with semen samples containing $>1 \times 10^{6}$ round cells $/ \mathrm{mL}$ were excluded to avoid a potential source of ROS generation. All female partners had patent fallopian tubes and experienced regular ovulation. In addition, results of semen samples from 91 normal healthy volunteers (donors) were used as the control for this study.

\section{Semen analysis}

Semen was collected by masturbation after 2 to 3 days of sexual abstinence. After liquefaction, semen analysis was performed both manually and by computerized semen analysis (CASA) (IVOS, 10.7s, Hamilton Thorne Research, Beverly, MA). For each measurement, a $5 \mu \mathrm{L}$ aliquot from either a control or infertile patient sample was loaded on a MicroCell slide (Conception Technologies, San Diego, CA). Sperm motion kinetics measured by CASA included: sperm concentration $\left(10^{6} / \mathrm{mL}\right)$, percent motility, curvilinear velocity (VCL; $\mu \mathrm{m} / \mathrm{sec})$, straight-line velocity (VSL; $\mu \mathrm{m} / \mathrm{sec}$ ), average path velocity (VAP; $\mu \mathrm{m} / \mathrm{sec}$ ), linearity (LIN; percent), and amplitude of lateral head displacement $(\mathrm{ALH} ; \mu \mathrm{m})$. In addition to the computerized results, manual results were also calculated for sperm concentration and motility.

For morphological evaluation, seminal smears were stained with Giemsa stain (Diff-Quik, Baxter Healthcare Corporation, McGraw Park, IL), and the percent sperm with normal morphology was assessed by WHO guidelines ${ }^{2}$ and Kruger's strict criteria. ${ }^{18}$

\section{Measurement of Reactive Oxygen Species}

Aliquots of liquefied semen were centrifuged at 300x g for 7 minutes. The sperm pellet was washed twice with phosphate buffered saline (PBS), pH 7.4, and resuspended in the same medium at a concentration of $20 \times 10^{6} \mathrm{sperm} / \mathrm{mL}$. ROS production was measured by the chemiluminescence assay method using luminol (5-amino-2, 3-dihydro 1, 4phthalazinedione; Sigma Chemical Co., St. Louis, MO) as the probe. Ten $\mathrm{mL}$ of $5 \mathrm{mM}$ luminol prepared in dimethyl sulfoxide (DMSO; Sigma Chemical Co.) was added to 400 $\mathrm{mL}$ of the washed sperm suspension. The ROS levels were determined by measuring chemiluminescence with a luminometer (Autolumat LB 953, Berthold technologies, Bad-Wildbad, Germany) in the integrated mode for 15 minutes. Results were expressed as $10^{4}$ counted photons per minute $(\mathrm{cpm}) / 20 \times 10^{6}$ sperm. These were $\log$ transformed $[\log (\mathrm{ROS}+1)]$, hereafter referred as ROS for simplicity, and were used in statistical analysis.

\section{Statistical Analysis}

A principal component analysis model was employed to calculate an overall SQ score that accounts for most of variability observed among the battery of interrelated semen variables. Details of the SQ score calculation are described in our previous study. ${ }^{11}$ In brief, this score was calculated by base 10 logarithms multiplied by varying 
weights given to the 9 sperm parameters: concentration, motility, sperm morphology according to WHO guidelines, and Tygerberg strict criteria, VCL, VSL, VAP, LIN, and ALH.

The SQ score and ROS level comparisons between groups were made using unpaired $t$ tests, while correlations between variables were assessed using Pearson's correlation coefficient. In addition, the sensitivity, specificity, positive predictive value (PPV), and negative predictive value (NPV) were also calculated. Receiver operating characteristic (ROC) curves, such as the area under the curve (AUC), were calculated to summarize the inherent capacity of the sperm quality variables to discriminate patients with MFI from the control donors. The SQ score along with ROS and sperm parameters were compared using De Long's nonparametric comparisons. ${ }^{19}$ Calculations were performed with GraphPad InStat version 3.00 statistical software (GraphPad Software, Inc., San Diego, CA) and StatsDirect (StatsDirect Ltd., Gresham Way, UK). A $P$ value $<.05$ was considered statistically significant.

\section{RESULTS}

\section{Identification of MFI patients with SQ score}

The SQ scores (mean \pm standard deviation) for the donors and patients are shown in Table 1. The SQ scores were significantly higher in the donors than in the MFI patients $(P<.001)$. Significantly lower SQ scores were observed in all groups of MFI patients compared with donors. The lowest SQ score was seen in the patients with OAT.

In order to determine whether the SQ score could differentiate MFI patients from control donors, we examined various cutoff values to determine the SQ score that would have the highest sensitivity. Table 2 displays various predictors of semen quality in 91 donors and 133 MFI patients using different cutoff values of the SQ score. Using a cutoff of 100 amongst the patient population, 93.23\% (124 of 133 ) of men had a SQ score $<100$, and only $7 \%$ (9 of 133) of the patients had a SQ score $>100$. At this cutoff, the sensitivity was high $(93.23 \%$ ), and the PPV (or the probability that a person having the disease given a positive test) was $70 \%$, with an accuracy (defined as the positively diagnosed MFI patients and correctly excluded donors) of $72 \%$. The specificity was, however, very low $(40.65 \%)$ at this cutoff. Lower cutoff values resulted in an increase in specificity with a corresponding decrease in sensitivity.

A cutoff of $\leq 93.1$ provided the optimum sensitivity of $80.45 \%$ and specificity of $70.32 \%$. When a cutoff of $\leq 93.1$ was used, the SQ score was able to correctly identify $80.45 \%$ of the patients as being MFI patients. Using this cutoff, the overall accuracy in differentiating the donors from the patients was $77 \%$ i.e. 150 of the 194 individuals

Table 1 - Reactive oxygen species (ROS) levels in donors and male factor infertility (MFI) patients and its correlation with semen quality score

\begin{tabular}{|c|c|c|c|c|c|c|}
\hline Study population & SQ score & $P$ value $^{\mathrm{a}}$ & ROS levels & $P$ value $^{\mathrm{b}}$ & $\begin{array}{l}\text { Correlation } \\
\text { coefficient }\end{array}$ & $P$ value $^{\mathrm{c}}$ \\
\hline Donors & $97.07 \pm 10.76(\mathrm{n}=91)$ & - & $1.20 \pm 0.80^{\mathrm{d}}(\mathrm{n}=76)$ & - & -0.45 & $<.001$ \\
\hline MFI patients & $75.56 \pm 18.55(n=133)$ & $<.001$ & $2.29 \pm 1.05(\mathrm{n}=121)$ & $<.001$ & -0.36 & $<.001$ \\
\hline Oligozoospermic & $64.70 \pm 14.93(n=61)$ & $<.001$ & $2.70 \pm 1.18(\mathrm{n}=57)$ & $<.001$ & -0.17 & .20 \\
\hline Asthenozoospermic & $70.55 \pm 18.00(n=96)$ & $<.001$ & $2.30 \pm 1.10(\mathrm{n}=90)$ & $<.001$ & -0.39 & .0002 \\
\hline Teratozoospermic & $66.82 \pm 16.50(n=69)$ & $<.001$ & $2.40 \pm 1.19(n=66)$ & $<.001$ & -0.39 & $<.001$ \\
\hline OAT & $56.01 \pm 12.69(n=38)$ & $<.001$ & $2.82 \pm 1.21(\mathrm{n}=35)$ & $<.001$ & -0.16 & 0.32 \\
\hline
\end{tabular}

*Values are mean $\pm \mathrm{SD}$; OAT $=$ oligoasthenoteratozoospermic; $\mathrm{SQ}=$ semen quality; ${ }^{\mathrm{a}} P<.05$ was considered significant comparing $\mathrm{SQ}$ score between donors and different groups of infertile patients; ${ }^{\mathrm{b}} P<.05$ was considered significant comparing ROS levels between donors and different groups of infertile population; ${ }^{c} P<.05$ was considered significant using Pearson correlation coefficient between SQ score and ROS levels; ${ }^{\circ} \log (\mathrm{ROS}+1)$ were used

Table 2 - Identification of male factor infertility patients using prediction parameters with different cutoff values

\begin{tabular}{|c|c|c|c|c|c|c|}
\hline Variable & Cutoff value & Sensitivity $(\%)$ & Specificity (\%) & PPV (\%) & NPV (\%) & Accuracy $(\%)$ \\
\hline \multicolumn{7}{|c|}{ SQ score cutoff } \\
\hline & 100 & 93.23 & 40.65 & 69.66 & 80.43 & 72 \\
\hline & 93.1 & 80.45 & 70.32 & 79.85 & 71.11 & 77 \\
\hline & 90 & 75.19 & 76.92 & 82.64 & 67.96 & 76 \\
\hline \multicolumn{7}{|c|}{ ROS levels } \\
\hline & 1 & 89.26 & 42.10 & 71.05 & 71.11 & 71 \\
\hline & 1.25 & 83.47 & 60.52 & 77.09 & 69.70 & 74.61 \\
\hline
\end{tabular}

$\overline{\mathrm{SQ}}=$ semen quality; ROS = reactive oxygen species; ROS values are $\log (\mathrm{ROS}+1) ; \mathrm{PPV}=$ Positive predictive value; NPV = Negative predictive value 
in our study population could be correctly categorized with this test (true positive and true negative).

Using an SQ score cutoff of $\leq 93.1$, we compared SQ score in this study population with normal sperm parameters with cutoff values established by WHO guidelines (2) i.e. sperm concentration ( $\geq 20 \times 10 \% \mathrm{~mL}$ ), motility ( $\geq 50 \%$ ) and WHO morphology ( $\geq 30 \%$ normal forms) (Table 3). Motility showed a sensitivity of $72.18 \%$ and specificity of $83.51 \%$. Using the WHO classification for sperm morphology, the sensitivity was $51.87 \%$ and the specificity was $87.91 \%$. On the other hand, Kruger's morphology had sensitivity of $82.70 \%$ but a very poor specificity $(26.37 \%)$.

\section{Identification of MFI patients using ROS levels}

Significantly higher levels of ROS $[\log (\mathrm{ROS}+1)]$ were seen within MFI patients, as well as in all the 4 subgroups, compared to donors $(P<.001)$ (Table 1$)$. The highest levels of ROS were seen in oligoasthenoteratozoospermic (OAT) patients. A strong negative correlation was seen between the SQ score and levels of ROS for donors $(\mathrm{r}=-0.45$, $P<.001)$ and MFI patients $(\mathrm{r}=-0.36, P<.001)$. A negative correlation was also seen in the asthenozoospermic and teratozoospermic patients (Table 1). Using an ROS cutoff of 1 , the sensitivity was $89.26 \%$, but the specificity in correctly identifying the infertile patients was poor (42.10\%). When the ROS cutoff was increased to 1.25 , the sensitivity decreased to $83.47 \%$, but the specificity increased along with accuracy (Table 1).

\section{Receiver operating characteristic (ROC) curves}

The effectiveness of the SQ score in differentiating the MFI patients from the normal healthy donors was studied by generating ROC curves (Table 4). Using a SQ score cutoff of d" 93.1 , the AUC was $84.28 \%$ with a $95 \%$ confidence interval (CI) of $65.22 \%$ to $100 \%$. The AUC using different sperm parameters and ROS cutoff of 1.25 is shown in Table 4. Sperm concentration and percent motility had a similar AUC. Both the AUC and 95\% CI were much lower for sperm morphology both by WHO criteria and Kruger's strict criteria (Fig. 1). The AUC for SQ score was higher (84.28\%) compared with that for ROS (78.92\%) (Fig. 2).

We were also interested to see whether we could arrive at the best cutoff values for sperm parameters in identifying MFI patients compared to the well-established WHO values for normal sperm parameters. By giving equal weight to sensitivity and specificity, the best cutoff values were provided by the statistical program. Using this method, a significantly different cutoff value was obtained for sperm concentration compared to the WHO cutoff value (Table 3 ). Using a cutoff value of $<49.80 \times 10^{6} / \mathrm{mL}$ for sperm concentration, the best sensitivity (79.69\%) was seen compared to $45.86 \%$ at the WHO defined cutoff of $<20 \times 10^{6} / \mathrm{mL}$.

Table 3 - Characteristics in correctly identifying the male factor infertility patients using calculated and World Health Organization (WHO) established cutoff for various sperm parameters

\begin{tabular}{|c|c|c|c|c|c|}
\hline Characteristic & Cutoff value & Sensitivity (\%) & Specificity $(\%)$ & PPV & NPV \\
\hline \multirow{2}{*}{ Sperm count $\left(\mathrm{X} 10^{6} / \mathrm{mL}\right)$} & $<20^{\mathrm{a}}$ & 45.86 & 94.50 & 92.42 & 54.43 \\
\hline & $\leq 49.80^{\mathrm{b}}$ & 79.69 & 71.42 & 80.30 & 70.65 \\
\hline \multirow{2}{*}{ Motility (\%) } & $<50^{\mathrm{a}}$ & 72.18 & 83.51 & 86.48 & 67.25 \\
\hline & $\leq 50^{\mathrm{b}}$ & 74.43 & 81.31 & 85.34 & 68.51 \\
\hline \multicolumn{6}{|l|}{ Morphology (\% normal forms) } \\
\hline \multirow[t]{2}{*}{ WHO morphology (\%) } & $<30^{a}$ & 51.87 & 87.91 & 86.25 & 55.55 \\
\hline & $\leq 29^{b}$ & 51.87 & 87.91 & 86.25 & 55.55 \\
\hline \multirow[t]{2}{*}{ Kruger's morphology (\%) } & $<14$ & 82.70 & 26.37 & 62.14 & 51.06 \\
\hline & $\leq 7^{\mathrm{b}}$ & 54.13 & 89.01 & 87.80 & 57.04 \\
\hline
\end{tabular}

${ }^{a}$ WHO cutoff values; ${ }^{\text {bC }}$ utoff values given by the statistical program; PPV = positive predictive value; NPV = negative predictive value

Table 4 - Areas under the curve (AUC) for semen quality (SQ) score and various sperm parameters

\begin{tabular}{llll}
\hline Variable & Cutoff value & AUC (\%) & $95 \%$ CI for AUC (\%) \\
\hline SQ cutoff score & 93.1 & 84.28 & $65.22-100$ \\
Log (ROS+1) & 1.25 & 78.92 & $72.60-85.23$ \\
Sperm count $\left(\times 10^{6} / \mathrm{mL}\right)^{\text {a }}$ & 20 & 81.31 & $63.62-99$ \\
Motility $(\%)^{\mathrm{a}}$ & 50 & 82.29 & $64.13-100$ \\
Morphology (\% normal forms) & & & $56.20-80.12$ \\
WHO morphology $(\%)^{\mathrm{a}}$ & 30 & 68.16 & $57.57-83.21$ \\
Kruger's morphology $(\%)$ & 14 & 70.39 & \\
\hline
\end{tabular}

WHO = World Health Organization; ${ }^{a}$ Cutoff values established by the WHO guidelines; ROS $=$ reactive oxygen species; $\mathrm{CI}=$ confidence interval 


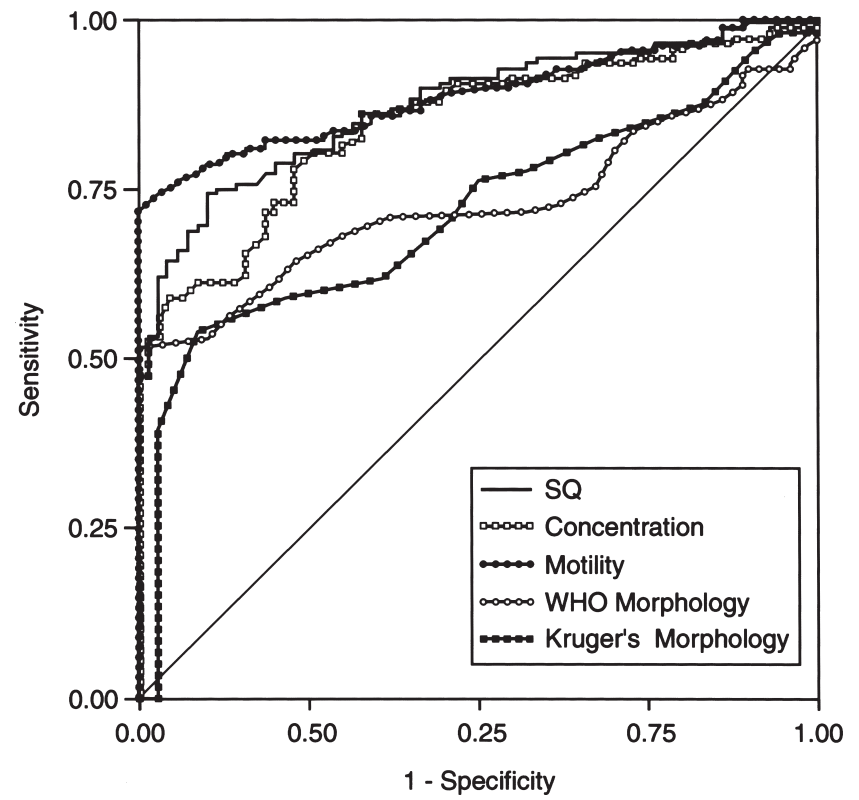

Figure 1 - Receiver operating characteristic curves showing the area under the curve in male factor infertility patients and normal healthy donors utilizing semen quality score and various parameters of sperm quality: (A) semen quality score, (B) concentration, (C) motility, (D) Kruger's morphology, and (E) World Health Organization morphology

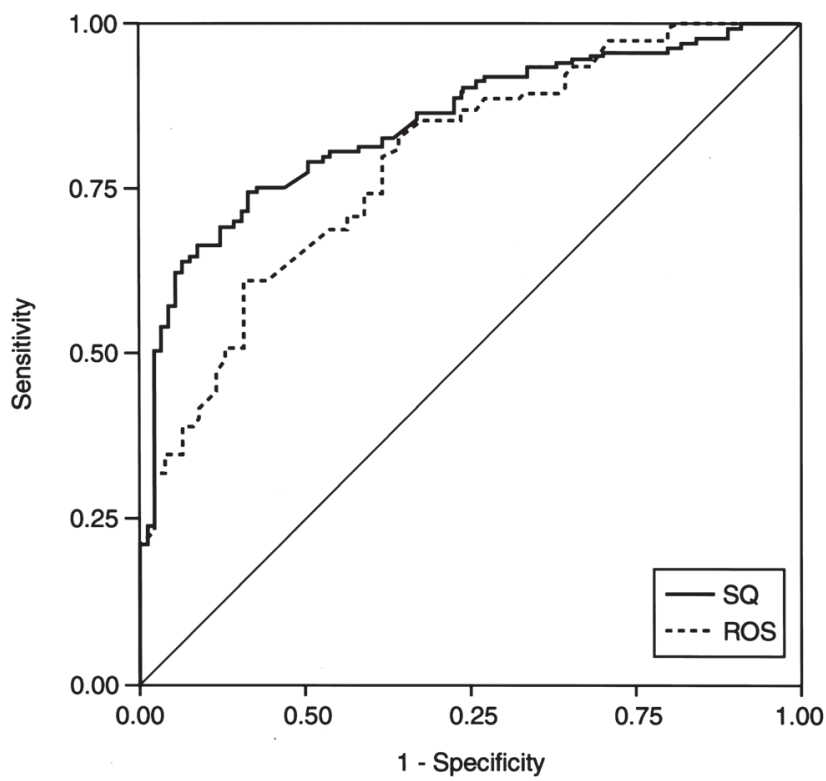

Figure 2 - Receiver operating characteristic curves showing the area under curve in male factor infertility patients and normal healthy donors using semen quality score and reactive oxygen species level

The cutoff values obtained by the statistical program for both motility and sperm morphology, however, were similar $(49.9 \%$ and $29 \%)$ to the WHO defined values of $50 \%$ and $30 \%$. These values were also comparable for sensitivity, specificity, positive predictive value, and negative predictive value. For sperm morphology by Kruger's strict criteria, a cutoff value of $7 \%$ had greater sensitivity and specificity than a cutoff of $14 \%$ in correctly identifying the MFI patients.

\section{DISCUSSION}

The role of traditional semen analysis and individual sperm parameters in identifying fertile and infertile men is a matter of ongoing debate. Several studies have reported the predictive values of individual sperm parameters such as concentration of motile spermatozoa ${ }^{20,21}$ and computerized measurements of different patterns of spermatozoa motility $^{22-24}$ and morphology $y^{25-28}$ to aid in the determination of male fertility and infertility. There is no consensus within the literature on the cutoff values of any individual parameter in defining patients with MFI from fertile males. ${ }^{29}$ It appears that there is a need to establish a combined value for all these sperm parameters (concentration, motility, and morphology) into a single score that can explain semen analysis results effectively and help establish the status of the individual who comes to the infertility screening. This approach would be helpful both to the clinician and the patient.

Because a screening test is used to identify a maximum number of patients during routine evaluation, the test must be sensitive so that it can identify all true positives (number of patients identified as being patients) at a given cutoff point. Our results show that the SQ score was able to predict MFI patients with the best sensitivity $(80.45 \%)$ along with ROS (83.47\%) at given cutoff points of 93.1 and 1.25 , respectively. All the sperm parameters had lower sensitivities in identifying the MFI patients when WHO-defined cutoff points were used versus the SQ score and ROS.

Using the $10^{\text {th }}$ percentile for the donors, we found that the lower limit of normality for the SQ score was 84.38 while the upper limit $\left(90^{\text {th }}\right.$ percentile) in MFI patients was 96.79. This indicates that only $10 \%$ (9 of 91) of the donors have a score $<84.38$ and that $11 \%$ of MFI patients (14 of 133) had an SQ score $>96.79$. Overlapping of normal and abnormal SQ scores between 2 groups is unavoidable using sperm parameters and SQ scores. Using a SQ cutoff score of 93.1 , only $12 \%(29 / 224)$ of our study population had false positive results; that is, subjects who tested positive but were actually negative. These individuals will, however, be considered MFI patients. Similarly, by using this cutoff, only $12 \%$ (26 of 224) of the patient population fell in the category of normal healthy donors. Therefore, an SQ score with a cutoff of 93.1 can better discriminate MFI patients from normal, healthy donors. As a result, this cutoff can serve as an effective screening tool during routine infertility evaluation. Furthermore, using the AUC for the SQ score indicated the probability of correctly identifying MFI patients 
and donors into their respective categories. The AUC for SQ $(84.28 \%$ ) was better than the AUC for ROS (78.92\%) and other sperm parameters (Table 4). Sperm function tests like the sperm penetration assay, sperm zona pellucida binding assay, $^{30}$ and acrosome reaction ${ }^{31}$ also correlate well with MFI diagnosis and have a definite place in the evaluation of the infertile male. However, because they are expensive and difficult to perform, they can be used only in specific circumstances or research settings but not as routine screening tests in an andrology laboratory.

Sperm measurements that discriminate between fertile and infertile men are not well defined. ${ }^{26,29}$ Moreover, an extensive overlap was seen between the fertile and the infertile men within both the subfertile and the fertile ranges for all 3 measurements. We found that with current cutoff values, sperm concentration and Kruger's morphology showed either poor sensitivity $(45.86 \%$ for sperm concentration) or poor specificity (26.37\% for Kruger's morphology) in identifying MFI patients from normal healthy donors. When sensitivity and specificity were weighted equally, the best cutoff values provided by statistical program for these parameters were significantly different from current cutoff values $(\leq 49.80$ for sperm concentration and $\leq 7$ for Kruger's morphology).

Another interesting finding from our study was that, of all the sperm parameters, sperm motility had the best sensitivity and specificity at a WHO-defined cutoff point (sensitivity of $72.18 \%$, specificity of $83.51 \%$ ) and was close to the cutoff value derived by the statistical program.

Seminal ROS levels are a real concern because they are potentially toxic to sperm quality and function at high levels. ${ }^{32,33}$ Several studies reported that increased formation of ROS is correlated with a reduction of sperm motility. ${ }^{34-36}$ Other studies failed to confirm these findings. ${ }^{37}$ Similarly, several studies reported a correlation between sperm concentration and increased production of ROS in infertile patients, ${ }^{38-41}$ which other authors failed to confirm. ${ }^{37}$ In our study, we found a significant correlation between the SQ score derived from sperm parameters and ROS levels in all the MFI patients. The correlation increased as the amount of abnormal spermatozoa increased and motility decreased (Table 1).

An important implication of our study is that the SQ score was developed from individual sperm parameters. Therefore, this score provides us with an overall indicator of spermatozoa quality in any given semen sample, which may not be appreciated by examining a single parameter. In addition, the production of ROS depends on the overall quality of the spermatozoa in a given semen sample and not on any individual sperm parameter. This explains the good correlation between SQ scores and ROS levels. Since the production of ROS depends on the overall quality of semen, we used ROS levels to discriminate donors and MFI patients. The clinical significance of our study lies in identifying parameters that accurately differentiate infertile male patients.

The main limitation of our study was that it was retrospective in nature. In addition, we did not have proven fertile donors to use as controls; consequently, we used normal healthy donors instead. These donors were selected based on the fact that they did not present to our male infertility clinic. However, not all of the donors exhibited normal semen characteristics defined by WHO guidelines for normal, healthy donors. A prospective study using proven fertile donors is needed to evaluate the efficacy of the SQ score and ROS levels as new tools in screening for male factor infertility.

In conclusion, our study demonstrates that the SQ score and ROS levels are highly correlated with MFI and are better discriminators of MFI than individual sperm parameters. Both of these parameters show better sensitivity than the individual sperm parameters in identifying infertile patients and should be included in routine infertility screening.

\section{ACKNOWLEDGEMENTS}

The authors thank Dr. Nabil Aziz, M.D. for his assistance in the analysis of ROC curves. Karen Seifarth, MT (ASCP), Cheryl Ackerman, MT (ASCP), and Lora Cordek, MT (ASCP) from the Clinical Andrology Laboratory provided technical help and Robin Verdi provided secretarial help.

\section{RESUMO}

Nallella KP, Sharma RK, Allamaneni SSR, Agarwal A. Identificação de pacientes portadores do fator de infertilidade masculina através do cálculo de um novo escore de qualidade de sêmen e pela medida de espécies reativas de oxigênio. Clinics. 2005:60(4):317-24.

OBJETIVO: Determinar se pacientes portadores do fator de infertilidade masculina podem ser precisamente identificados através do cálculo de um novo escore de qualidade de sêmen e pela medida de espécies reativas de oxigênio durante uma avaliação rotineira de infertilidade.

MÉTODOS: Amostras de sêmen de 133 pacientes e de 91 doadores saudáveis foram avaliadas através de análise manual e computadorizada de sêmen. Um modelo de análise 
do componente principal foi empregado para calcular o escore de qualidade de sêmen, utilizando logaritmos base 10, multiplicados por ponderações variáveis de 9 parâmetros espermáticos. Os níveis de espécies reativas de oxigênio foram medidos através de testes de quimiluminescência.

RESULTADOS: O escore de qualidade de sêmen apresentou sensibilidade de $80.45 \%$ e precisão de $77 \%$ para um “cutoff” de 93.1 na identificação do fator de infertilidade masculina. A área sob a curva "receiver operating characteristic" para o escore de qualidade de sêmen foi de $84.28 \%$ (95\% intervalo de confiança: $65.22 \%-100 \%$ ). Os níveis de espécies reativas de oxigênio [log10 (espécies reativas de oxigênio +1 )] foram siginificativamente mais elevados nos pacientes portadores de fator de infertilidade masculina. A medica de espécies reativas de oxigênio apresentou sensibilidade de $83.47 \%$ e especificidade de $60.52 \%$ com uma precisão (definida como pacientes portadores do fator de infertilidade masculina com diagnóstico positivo e doadores corretamente excluídos) de $75 \%$ para um "cutoff" de 1.25 na identificação de pacientes portadores do fator de infertilidade masculina. A área sob a curva "receiver operating characteristic" para níveis de espécies reativas de oxigênio foi de $78.92 \%$ (95\% intervalo de confiança: $72.60 \%-85.23 \%$ ). Os escores de qualidade de sêmen correlacionaram negativamente com os níveis de espécies reativas de oxigênio tanto nos doadores e nos pacientes portadores do fator de infertilidade masculina.

CONCLUSÕES: O escore de qualidade de sêmen e os níveis espécies reativas de oxigênio nas amostras de sêmen parecem associar-se fortemente com o fator de infertilidade masculina. Na medida em que os dois parâmetros mostraramse mais sensíveis que parâmetros espermáticos individuais na identificação do fator de infertilidade masculina, deveriam ser incluídos na avaliação rotineira de infertilidade.

\section{UNITERMOS: Espermatozóide. Fator de infertilidade masculina. Escores de qualidade de sêmen. Espécies reativas de oxigênio. Parâmetros espermáticos.}

\section{REFERENCES}

1. Sharlip ID, Jarow JP, Belker AM, Lipshultz LI, Sigman M, Thomas AJ, et al. Best practice policies for male infertility. Fertil Steril. 2002;77:873-82.

2. World Health Organization. Laboratory manual for the examination of human semen and sperm-cervical mucus interaction. 4th ed. New York: Cambridge University Press, 1999.

3. Marchini M, Losa G, Falcone L, Piffaretti-Yanez A, Zeeb M, Balerna M. Etiology of severe asthenozoospermia and fertility prognosis. A screening of 5216 semen analyses. Andrologia. 1991;23:11520

4. McLachlan RI, Baker HW, Clarke GN, Harrison KL, Matson PL, Holden CA, et al. Semen analysis: its place in modern reproductive medical practice. Pathology. 2003;35:25-33.

5. Coetzee K, Kruge TF, Lombard CJ. Predictive value of normal sperm morphology: a structured literature review. Hum Reprod Update. 1998;4:73-82.

6. Verstegen J, Iguer-Ouada M, Onclin K. Computer assisted semen analyzers in andrology research and veterinary practice. Theriogenology. 2002;57:149-79.

7. Irvine DS. Computer assisted semen analysis systems: sperm motility assessment. Hum Reprod. 1995;10:53-59.

8. De Geyter C, De Geyter M, Koppers B, et al. Diagnostic accuracy of computer-assisted sperm motion analysis. Hum Reprod. 1998;13:2512-20.

9. Mortimer D, Aitken RJ, Mortimer ST, et al. Workshop report: clinical CASA - the quest for consensus. Reprod Fertil Dev. 1995; 7:951-9.

10. Guzick D, Sullivan M, Adamson G, et al. Efficacy of treatment for unexplained infertility. Fertil Steril. 1998;70:207-13.
11. Agarwal A, Sharma RK, Nelson DR. New semen quality scores developed by principal component analysis of semen characteristics. J Androl. 2003;24:343-52.

12. Padron OF, Brackett NL, Sharma RK, et al. Seminal reactive oxygen species and sperm motility and morphology in men with spinal cord injury. Fertil Steril. 1997;67:1115-20.

13. Sharma RK, Agarwal A. Role of reactive oxygen species in male infertility. Urology. 1996;48:835-50.

14. Alkan I, Simsek F, Haklar G, Kervancioglu E, Ozveri H, Yalcin S, et al. Reactive oxygen species production by the spermatozoa of patients with idiopathic infertility: relationship to seminal plasma antioxidants. J Urol. 1997;157:140-3.

15. Aitken RJ, Clarkson JS, Fishel S. Generation of reactive oxygen species, lipid peroxidation, and human sperm function. Biol Reprod. $1989 ; 41: 183-97$

16. Aitken RJ, Buckingham D, West K, Wu FC, Zikopoulos K, Richardson DW. Differential contribution of leucocytes and spermatozoa to the generation of reactive oxygen species in the ejaculates of oligozoospermic patients and fertile donors. J Reprod Fertil. 1992;94:451-62.

17. Pasqualotto FF, Sharma RK, Kobayashi H, Nelson DR, Thomas AJ Jr, Agarwal A. Oxidative stress in normospermic men undergoing infertility evaluation. J Androl. 2001;22:316-22.

18. Kruger TF, Acosta AA, Simmons KF, Swanson RJ, Matta JF, Veeck LL, et al. New method of evaluating sperm morphology with predictive value for human in vitro fertilization. Urology. $1987 ; 30: 248-51$

19. DeLong D. Comparing the areas under two or more correlated receiver operating curves: A nonparametric approach. Biometrics. 1998;44:837-45. 
20. Menkveld R, Wong WY, Lombard CJ, Wetzels AM, Thomas CM, Merkus HM, et al. Semen parameters, including WHO and strict criteria morphology, in a fertile and subfertile population: an effort towards standardization of in-vivo thresholds. Hum Reprod. 2001;16:1165-71.

21. Liu DY, Clarke GN, Baker HW. Relationship between sperm motility assessed with the Hamilton-Thorn motility analyzer and fertilization rates in vitro. J Androl. 1991;12:231-39.

22. Macleod IC, Irvine DS. The predictive value of computer-assisted semen analysis in the context of a donor insemination programme. Hum Reprod. 1995;10:580-86.

23. Krause W. Computer-assisted semen analysis systems: comparison with routine evaluation and prognostic value in male fertility and assisted reproduction. Hum Reprod. 1995;10:60-66.

24. Irvine DS, Macleod IC, Templeton AA, Masterton A, Taylor A. A prospective clinical study of the relationship between the computerassisted assessment of human semen quality and the achievement of pregnancy in vivo. Hum Reprod. 1994;9:2324-34.

25. Mortimer D, Menkveld R. Sperm morphology assessmenthistorical perspectives and current opinions. J Androl. 2001;22:192205.

26. Bonde JP, Ernst E, Jensen TK, Hjollund NH, Kolstad H, Henriksen $\mathrm{TB}$, et al. Relation between semen quality and fertility: a populationbased study of 430 first-pregnancy planners. Lancet. 1998;352:1172-7.

27. Eggert-Kruse W, Schwarz H, Rohr G, Demirakca T, Tilgen W, Runnebaum B. Sperm morphology assessment using strict criteria and male fertility under in-vivo conditions of conception. Hum Reprod. 1996;11:139-46.

28. Grow DR, Oehninger S, Seltman HJ, Toner JP, Swanson RJ, Kruger TF, et al. Sperm morphology as diagnosed by strict criteria: probing the impact of teratozoospermia on fertilization rate and pregnancy outcome in a large in vitro fertilization population. Fertil Steril. 1994;62:559-67.

29. Guzick DS, Overstreet JW, Factor-Litvak P, Brazil CK, Nakajima ST, Coutifaris C, et al. Sperm morphology, motility, and concentration in fertile and infertile men. N Engl J Med. 2001;345:1388-93.
30. Coddington CC, Oehninger SC, Olive DL, Franken DR, Kruger TF, Hodgen GD. Hemizona index (HZI) demonstrates excellent predictability when evaluating sperm fertilizing capacity in vitro fertilization patients. J Androl. 1994;15:250-54.

31. Cummins JM, Pember SM, Jequier AM, Yovich JL, Hartmann PE. A test of the human sperm acrosome reaction following ionophore challenge. Relationship to fertility and other seminal parameters. J Androl. 1991;12:98-103.

32. Aitken RJ. A free radical theory of male infertility. Reprod Fertil Dev. 1994;6:19-23.

33. Iwasaki A, Gagnon C. Formation of reactive oxygen species in spermatozoa of infertile patients. Fertil Steril. 1992;57:409-16.

34. Agarwal A, Ikemoto I, Loughlin KR. Relationship of sperm parameters with levels of reactive oxygen species in semen specimens. J Urol. 1994;152:107-10.

35. Comhaire FH, Mahmoud AM, Depuydt CE, Zalata AA, Christophe $\mathrm{AB}$. Mechanisms and effects of male genital tract infection on sperm quality and fertilizing potential: the andrologist's viewpoint. Hum Reprod Update. 1999;5:393-8.

36. Armstrong JS, Rajasekaran M, Chamulitrat W, Gatti P, Hellstrom WJ, Sikka SC. Characterization of reactive oxygen species induced effects on human spermatozoa movement and energy metabolism. Free Radic Biol Med. 1999;26:869-80.

37. Tomlinson MJ, Barratt CL, Cooke ID. Prospective study of leukocytes and leukocyte subpopulations in semen suggests they are not a cause of male infertility. Fertil Steril. 1993;60:1069-75.

38. Kessopoulou E, Tomlinson MJ, Barratt CL, Bolton AE, Cooke ID. Origin of reactive oxygen species in human semen: spermatozoa or leucocytes? J Reprod Fertil. 1992;94:463-70.

39. Potts JM, Sharma R, Pasqualotto F, Nelson D, Hall G, Agarwal A Association of ureaplasma urealyticum with abnormal reactive oxygen species levels and absence of leukocytospermia. J Urol. 2000;163:1775-78.

40. Henkel R, Schill WB. Sperm separation in patients with urogenital infections. Andrologia. 1998;30:91-7.

41. Aitken RJ, West KM. Analysis of the relationship between reactive oxygen species production and leukocyte infiltration in fractions of human semen separated on Percoll gradients. Int J Androl. 1990; 13:433-51. 